\title{
O IMPACTO DAS INOVAÇÕES NO DESENVOLVIMENTO ECONÔMICO BRASILEIRO
}

\author{
Stefano José Caetano da SILVEIRA* \\ *Economista graduado pela UFRGS, Mestre em Economia do Desenvolvimento (PPGE-UFRGS); e-mail: \\ $\underline{\text { stefano.caetano@gmail.com }}$
}

Recebido em: 23/09/2014 - Aprovado em: 27/11/2014 - Disponibilizado em: 15/12/2014

Resumo: A proposta deste artigo foi apresentar uma análise do impacto das inovações no desenvolvimento econômico brasileiro, abordando seu conceito, suas origens e sua classificação, bem como exemplos de companhias inovadoras nacionais e estrangeiras reconhecidamente inseridas nesse contexto. Para tanto, efetuou-se uma breve revisão da bibliografia existente sobre o tema. Com base nesse arcabouço, buscou-se demonstrar que a inovação nos dias atuais possui a mesma importância que a industrialização teve para os países periféricos durante o século XX. Ou seja, assim como no Brasil do século passado industrialização rimava com desenvolvimento, agora é a inovação que faz esse papel.

Palavras-chave: Inovação. Desenvolvimento. Crescimento. Competitividade. Resultado.

\section{The Impact of Innovations in the Brazilian Economic Development}

\begin{abstract}
The purpose of this paper was to present an analysis of the impact of innovations in the Brazilian economic development, addressing its concept, its origins and classification, as well as examples of inserted known domestic and foreign innovative companies in this context. To do so, we performed a brief review of existing literature on the subject. Based on this framework, we sought to demonstrate that innovation nowadays has the same importance that industrialization had to peripheral countries during the twentieth century. Ie, as in Brazil the last century industrialization rhymed with development, now is the innovation that makes this role.
\end{abstract}

Keywords: Innovation. Development. Growth. Competitiveness. Result.

\section{Introdução}

O crescimento econômico, o desenvolvimento e o bem-estar das nações dependem da geração, da exploração e da difusão de conhecimento. O conhecimento, que exerce um papel central na economia global, necessita estar ao alcance das

\begin{abstract}
pessoas e das empresas. Entre os instrumentos para que este objetivo seja alcançado destaca-se a inovação, definida por uma das principais referências no assunto, o Manual de Oslo (OECD, 2005, p.
\end{abstract} 55), como: 
[...] a implementação de um produto (bem ou serviço) novo ou significativamente melhorado, ou um processo, ou um novo método de marketing, ou um novo método organizacional nas práticas de negócios, na organização do local de trabalho ou nas relações externas.

O requisito mínimo para se definir uma inovação é que ela seja nova ou significativamente melhorada. Isso inclui inovações desenvolvidas de forma pioneira no interior da firma, bem como aquelas que são adotadas a partir de outras empresas ou organizações. De acordo com Tidd et al. (2008), a inovação é um processo essencialmente preocupado em renovar o que a empresa oferece (seus bens e/ou serviços) e a forma como eles são fabricados e vendidos, transformando oportunidades em novas ideias e colocando-as em prática. Em outras palavras, a inovação envolve a identificação de oportunidades, a materialização de ideias que correspondam a essas necessidades e, finalmente, a sua comercialização em forma de produtos. Dado a possibilidade de a empresa promover diversas modificações em seus métodos de trabalho e na empregabilidade de seus fatores de produção, redundando no incremento de sua produtividade e/ou de seu desempenho comercial, o Manual de Oslo (OECD, 2005) classifica as inovações em quatro tipos, de acordo com o ramo de atividades das empresas: inovações de produto, inovações de processo, inovações organizacionais e inovações de marketing.

As inovações de produto englobam mudanças consideráveis nas potencialidades de bens e serviços, tanto novos como significativamente aperfeiçoados (ex: Nota Fiscal Eletrônica). Já as inovações de processo dizem respeito às mudanças tanto dos métodos de produção como de distribuição (ex: entrega de produtos a domicílio). Em relação às inovações organizacionais, destaca-se a adoção de novos métodos organizacionais, abrangendo tanto as mudanças em práticas de negócios e na organização do local de trabalho como nas relações externas da empresa (ex: adoção da horizontalização em detrimento à verticalização em diversas instituições). Por fim, citam-se as inovações de marketing que envolvem a implementação de novos métodos de marketing, indo desde o design do produto e sua embalagem até sua promoção e colocação no mercado (ex: a criação, em 1931, do Papai Noel da CocaCola; um velhinho com um sorriso 
amigável, gorducho e nórdico, vestido com as cores do produto).

Como exemplos de inovações no mercado brasileiro - gerando ganhos econômicos, sociais e ambientais - podem ser citados a difusão de bens e serviços associados à informática (como os servidores virtuais) e telecomunicações (televisão digital e smartphones), permitindo a ampliação das possibilidades de comunicação, aprendizagem e negócios, bem como a redução dos custos e das desigualdades socioeconômicas, o aumento da competitividade da economia, e o arrefecimento do chamado "custo Brasil" (KNIGHT; FERNANDES, 2006).

Dessa forma, o objetivo deste artigo é analisar o impacto das inovações no desenvolvimento econômico brasileiro, abordando seu conceito, suas origens e sua classificação, bem como exemplos de companhias inovadoras nacionais e estrangeiras. Para isso, buscou-se demonstrar que a inovação nos dias atuais possui a mesma importância que a industrialização teve para os países periféricos durante o século XX. Ou seja, assim como no Brasil do século passado industrialização rimava com desenvolvimento, agora é a inovação que faz esse papel.

\section{Antecedentes}

A implementação de inovações na busca do desenvolvimento econômico e social no Brasil, a partir da entrada do real como novo padrão monetário, em 1994, não pode ser tomada como novidade, caso as políticas de incentivo à geração e implantação de progresso técnico sejam consideradas precursoras do citado período. Ao longo da história, em distintos momentos, o País viveu esta experiência. Em 1931, com o presidente Getúlio Vargas (1930-1945; 1951-1954), foi posto em prática o Processo de Substituição de Importações (PSI) ${ }^{1}$, com a ideia de fazer crescer a economia, pois naquele momento, desenvolvimento era sinônimo de industrialização. Dessa maneira, para que este processo obtivesse êxito, algumas ações foram implementadas no setor industrial brasileiro, seja através da importação de bens de capital, seja pelas novas técnicas produtivas adotadas. Da mesma forma, durante o governo Juscelino Kubitscheck

\footnotetext{
${ }^{1}$ Para Celso Furtado, mesmo com a inauguração de algumas fábricas no Brasil antes de 1930 - como as do setor têxtil - e do pioneirismo do Barão de Mauá (1813-1889), a partir do PSI iniciou-se a transição de um modelo agroexportador (a chamada economia para fora) para um modelo industrial interno
} 
(1956-1961), o Brasil foi sacudido por uma onda transformadora chamada Plano de Metas (cujo lema era "50 anos em 5"), que permitiu o aumento da produtividade e o desenvolvimento da indústria automobilística e da rede energética, a construção de uma malha viária nacional e a mudança da capital federal para o centro do país. Além destas, outras medidas modernizadoras podem ser mencionadas, como as contidas nos dois primeiros Planos Nacionais de Desenvolvimento (I e II PND), que permitiram a expansão e a consolidação do parque industrial brasileiro (FURTADO, 1987; FONSECA, 1999; REZENDE, 1999).

Com o começo do processo de abertura econômica promovido pelo governo do presidente Fernando Collor de Mello (1990-1992), que sepultou definitivamente a ideia do "estado empreendedor", além de exigir uma rápida e severa adaptação das empresas nacionais a este novo paradigma, iniciou-se um período transitório de quedas paulatinas e graduais nas taxas de importação, que culminaram, em 1992, com o fim da reserva do mercado de informática (BELLUZZO; ALMEIDA, 2002). Todavia,

\footnotetext{
${ }^{2}$ O liberalismo do governo Collor pode ser entendido como um rompimento definitivo com a herança getulista, apesar da preservação de algumas regras do período de Getúlio Vargas, como a Consolidação das Leis do Trabalho (CLT).
}

segundo Coutinho e Ferraz (1994), cerca de $70 \%$ das empresas envolvidas no Estudo de Competitividade da Indústria Brasileira $(\mathrm{ECIB})$ - de autoria de ambos - buscaram lograr competitividade diante desse novo cenário, realizando incipientes reestruturações na busca por inovações, sem, contudo, atingir os padrões internacionais ${ }^{3}$. Ainda, segundo eles, o principal instrumento para a mudança geral da economia - a abertura comercial - foi pouco decisivo nas mudanças da estrutura industrial brasileira do principio dos anos 1990, principalmente quanto à capacitação produtiva pelo uso de tecnologias mais avançadas.

Por outro lado, a partir da entrada em vigor do Plano Real, durante o governo Itamar Franco (1992-1994), dentro de um contexto de globalização econômica, o Brasil experimentou um considerável avanço tecnológico em termos produtivos, galgado na importação de bens de capital que possibilitaram a operacionalização de processos conhecidos como learning by doing $^{4}$ e catching up ${ }^{5}$. Os avanços

\footnotetext{
3 Boa parte destes ajustes pode ser creditada à retração do mercado interno e ao aumento das exigências dos consumidores (COUTINHO; FERRAZ, 1994).

4 O termo learning by doing (aprender fazendo) está relacionado ao conceito de progresso tecnológico, dado que o mesmo considera que a taxa e o
} 
proporcionados pela tecnologia, além das novidades em termos técnicos, geraram novos produtos e novas condições de vida, disponibilizando recursos que, ao interagirem entre si, deram origem ao termo Tecnologia de Informação e Comunicação (TIC) - cuja adoção pode reverter em um aumento de produtividade do trabalho e de conhecimento, gerando ganhos no setor econômico no qual o usuário estiver inserido, através do incremento da renda e do produto - que quando empregadas no setor público, fazem surgir o conceito de $e$ $G o v^{6}$ (governo eletrônico, e-governo ou egovernança) (SOUZA, 2005; MENDES, 2007; KNIGHT; FERNANDES, 2006).

da estrutura e da natureza dos trabalhos em pesquisa e desenvolvimento. Nesse particular, pesquisa corresponde à criação de novos produtos ou novas técnicas de produção e desenvolvimento na transformação da pesquisa em prática (SOUZA, 2005).

5 Segundo Lemos et al (2006, p.59): "O conceito de catching up $[\ldots]$ compreende a capacidade de centros secundários de absorver técnicas e conhecimentos gerados nos centros líderes, de forma a permitir que aqueles 'alcancem' os níveis de produtividade destes $\mathrm{e}$, portanto, reduzam o hiato tecnológico (e de desenvolvimento econômico) que os separa".

${ }^{6}$ Segundo Knight e Fernandes (2006, p.16), governo eletrônico, e-governo, ou $e$-Gov, (do inglês electronic government), "[...] é uma concepção que assimila os potenciais das TICs na transformação da administração pública, com substancial melhoria da sua organização, dos seus serviços e do relacionamento com a sociedade. Essa concepção se insere numa perspectiva avançada de governança democrática, transparente e aberta à participação do cidadão."

\section{Análise a partir de Schumpeter}

Em seu livro "Teoria do Desenvolvimento Econômico" (TDE), de 1911, o economista tcheco Joseph Alois Schumpeter (1883-1950) defende o que ele chamou de "fenômeno fundamental" do desenvolvimento. Relacionando o processo de desenvolvimento econômico a mudanças endógenas - pois não lhe são impostas de fora $^{7}$ - e descontínuas do sistema produtivo - que alteram e deslocam o estado de equilíbrio da economia - desviou sua análise do fluxo circular ${ }^{8}$, pois o mesmo estuda apenas a tendência do sistema para o equilíbrio e suas pequenas e constantes adaptações, ficando sem explicar a

7 Furtado (1987) creditava ao PSI a passagem da economia brasileira de um modelo agroexportador para um modelo industrial interno, dado um contexto de depressão global devido ao crash de 1929. Concordava com a análise de Schumpeter, pois a adoção do PSI foi definida internamente.

8 De acordo com Costa (2006, p.3): "Na economia do fluxo circular, [...] a vida econômica transcorre monotonamente, em que cada bem produzido encontra o seu mercado, período após período. Isso, contudo, não significa concluir que inexista crescimento econômico. Admitem-se incrementos na produtividade, decorrentes de aperfeiçoamentos no processo de trabalho e de mudanças tecnológicas contínuas na função de produção. Entretanto, essa base tecnológica já é conhecida, incorporada que foi com o tempo na matriz produtiva da economia. Os agentes econômicos apegam-se ao estabelecido, e as adaptações às mudanças ocorrem em ambiente familiar e de trajetória previsível. Nessas circunstâncias, de acordo com Schumpeter, mudanças econômicas substanciais não podem ter origem no fluxo circular, pois a reprodução do sistema está vinculada aos negócios realizados em períodos anteriores". 
ocorrência de revoluções produtivas e suas consequências. Segundo ele:

O desenvolvimento, no sentido em que o tomamos, é um fenômeno distinto, inteiramente estranho ao que pode ser observado no fluxo circular ou na tendência para o equilíbrio. É uma mudança espontânea e descontínua nos canais do fluxo, perturbação do equilíbrio, que altera e desloca para sempre o estado de equilíbrio previamente existente (SCHUMPETER, 1997, p. 75).

Inovações no sistema produtivo que revertem em desenvolvimento acontecem no lado da oferta. Estas inovações, que podem dar origem a um novo produto, a um novo método, a abertura de um mercado, à conquista de novas matérias-primas ou ao estabelecimento de uma nova organização produtiva, ocorrem a partir de novas combinações - também chamadas de empreendimentos - de materiais e forças, surgindo repentinamente $\mathrm{e}$ de forma descontínua, remetendo ao aparecimento do desenvolvimento socioeconômico, pois causam alterações sociais e econômicas.
Neste ponto, torna-se importante ressaltar a diferença entre invenção e inovação. Enquanto a primeira refere-se a descobertas que não necessariamente influenciam a economia, a outra provém de novas combinações de fatores de produção que provocam desenvolvimento econômico, social e ambiental (SCHUMPETER, 1997).

Considerando-se um fluxo circular em equilíbrio - como o proposto pelo economista marginalista Léon Walras (1834-1910), autor da “Teoria do Equilíbrio Geral" - sem capacidade ociosa, onde a produção de um novo bem não pode ser financiada com recursos da produção passada e onde a poupança não apresenta um papel relevante, para que o novo bem possa ser produzido deve-se recorrer ao crédito, que, no sistema capitalista, pode ser obtido com seus ofertantes, os chamados capitalistas. Enquanto os capitalistas financiam, os empresários ou empreendedores conduzem o processo. Nesse particular, Possas (1999), em uma aproximação aos estudos de Porter (1989), analisa as empresas que conquistam inovações como possuidoras de vantagens de custos, dado as inovações propiciarem a elas maiores lucros por um determinado tempo pela execução de uma política de 
redução de preços, cujo objetivo é a ampliação de sua participação no mercado, e, ao mesmo tempo, impedirem a entrada de empresas concorrentes. Além disso, as inovações facultam às organizações que as empregam a possibilidade de conquistar lucros puros ou extraordinários por um determinado período também sob a estratégia de diferenciação, pois tendo produtos em que os clientes tenham preferência sem similar no mercado, possibilitam a estas empresas a cobrança de preços únicos.

Segundo Schumpeter (1997), os empresários - operadores de novas combinações de fatores produtivos - não devem ser confundidos com os proprietários de empresas que executam tarefas rotineiras sem contribuição alguma para 0 desenvolvimento. Não raro, diversos autores referem-se ao "empresário-schumpeteriano" como "empresário-inovador". Sob esta ótica, todos os que realizarem novas combinações que promovam desenvolvimento serão chamados de empresários. Para isto, deverão utilizar iniciativa, previsão, organização, intuição e liderança para enfrentar os problemas que encontrarem. Os indivíduos somente serão empresários enquanto permanecerem realizando novas combinações, pois se estiverem apenas gerenciando rotinas, passarão a ser classificados apenas como administradores de empresa. Sendo o ser humano resistente a mudanças, torna-se necessário que o empresário apresente seu espírito de liderança, para que o novo produto seja aceito pela sociedade, tornando-se uma inovação, bem como para que o capitalista lhe conceda crédito.

Ao longo dos tempos, diversos empresários-inovadores marcaram a história dos negócios, com inovações como o telefone de Alexander Graham Bell (18471922), a linha de montagem de Henry Ford (1863-1947), a fotografia instantânea de Edwin Land (1909-1991), a mágica da Disneylândia de Walt Disney (1901-1966), e os softwares desenvolvidos para computadores pessoais da Microsoft de Bill Gates (1955-) e da Apple de Steve Jobs (1955-2011). Porém, sem negar o valor gerado pelos pensamentos singulares, os dias atuais exigem muito mais que iniciativas individuais como as citadas neste parágrafo. Atualmente, faz-se necessário uma mudança de cultura, onde todos os envolvidos participem ativamente do processo inovatório. É necessário que a inovação assuma o caráter cooperativo 
(TAYLOR; LaBARRE, 2008).

\section{Companhias Inovadoras}

Taylor e LaBarre (2008) descrevem diversos casos de empresas que se desviaram do fluxo circular e apostaram em políticas inovadoras em seus segmentos de negócios. Na maioria das análises, a Internet surge como elemento imperioso para que tais ações ocorram. O ING Direct - um banco norte-americano que aposta em operações virtuais (cerca de $70 \%$ do total), devido ao nível atual de segurança das operações econômicas e financeiras que podem ser realizadas pela rede - cria vantagens competitivas enfatizando a rapidez, a simplicidade e os baixos custos. Essa instituição bancária não conta com locais físicos para atendimento, com caixas eletrônicos e executivos com altos salários, bem como com cobrança de taxas aos clientes e valores mínimos para depósitos. Pelo contrário, busca a eliminação da burocracia, exemplificada pela não utilização de papel (sempre que possível) e o oferecimento de um número restrito de produtos simples, como: cadernetas de poupança e certificados de depósitos bancários sem saldo mínimo; fundos de investimento, cujos portfólios podem ser classificados em conservadores, moderados e agressivos; além da possibilidade de adesão a hipotecas imobiliárias em apenas dez minutos. Contrariando o mainstream dominante, o ING tem conseguido se firmar no mercado - passando incólume pela crise financeira global $^{9}$ - incentivando seus clientes a economizar (TAYLOR; LaBARRE, 2008).

Da mesma forma, a companhia área Southwest, também dos Estados Unidos, têm conseguido resultados positivos e estáveis em um setor que vem passando por dificuldades há algum tempo, principalmente a partir dos atentados terroristas de 11 de setembro de $2001^{10}$. Todavia, diferentemente do ING, segundo Taylor e Labarre (2008, p.26): “O sucesso sem paralelos da empresa deve ser atribuído muito mais ao seu sistema de valores do que a tecnologia inovadora ou a uma inovação radical nos negócios". Em seus vôos, a

\footnotetext{
${ }^{9}$ Tal situação pode ser constatada ao longo de 2009 e nos primeiros meses de 2010.

10 No dia 11 de setembro de 2001, quatro aviões comerciais norte-americanos foram sequestrados por membros da rede terrorista Al-Qaeda, sendo dois deles lançados contra as torres gêmeas do World Trade Center - centro financeiro mundial - e um contra o Pentágono. O quarto avião seria lançado contra o Capitólio, porém acabou sendo derrubado pelos próprios passageiros ao enfrentarem os sequestradores. No total, os atentados vitimaram 3.234 pessoas, além de deixar 24 desaparecidos (nota do autor).
} 
empresa - cuja principal inovação foi tornar as viagens aéreas acessíveis a uma gama maior de pessoas - não disponibiliza serviços de primeira classe, lugares marcados e refeições a bordo. Esta política, que mantém os preços baixos e promoções de fácil compreensão, aliada ao bom atendimento prestado pelo corpo funcional da empresa - com seus sorrisos abertos, personalidades extrovertidas e senso de humor peculiares - garante o êxito da companhia. A Southwest comprova empiricamente a importância da adoção de políticas inovadoras: segundo a revista Money, um investimento de US\$ $10 \mathrm{mil} \mathrm{em}$ ações da Southwest em 1972 valia mais de US\$ 10 milhões cerca de três décadas depois.

Outro exemplo de uma empresa administrada por empresáriosschumpeterianos é a rede de televisão a cabo HBO. A companhia, que vem apresentando um robusto resultado financeiro desde a última década - lucro de US\$ 5 bilhões em 2013, além de uma média de 28,2 milhões de assinantes nos Estados Unidos - ocupa a liderança no mercado de TV a cabo. Isto pode ser creditado à política da rede de se vender aos espectadores, não se preocupando com questões como o público alvo que deseja atingir nem com índices de audiência, mas sim se sua programação é boa, original e diferente, sendo relevante para a experiência humana. Como exemplo disso, figuram seriados como "Sexy and the City", "Família Soprano" e "A Sete Palmos". De acordo com Taylor e Labarre (2008, p.41):

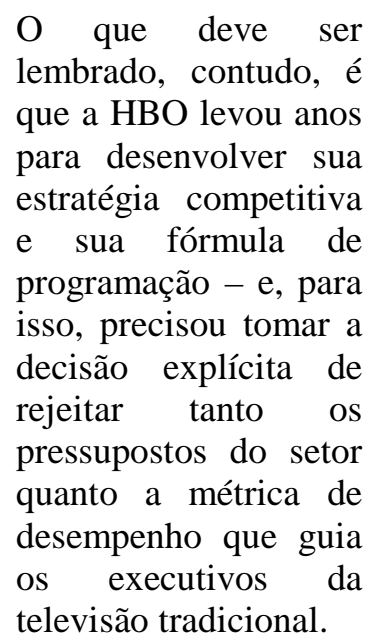

Isto ocorreu em 1999, quando Colin Callender e Chris Albrecht assumiram a produção de filmes. Ao perceberem que estavam sendo copiados pela concorrência, optaram por uma constante reinvenção, através do lançamento de títulos, tanto para o cinema como para televisão, que preenchiam os adjetivos sofisticado, inteligente, divertido e adulto. Dessa forma, a $\mathrm{HBO}$ criou e manteve uma vantagem competitiva em relação às suas rivais, 
buscando novas formas de produzir e apresentar programas no panorama digital emergente, formado por tecnologias transgressoras, que ocupam e preocupam os executivos de televisão. A HBO aposta na originalidade de suas ideias, onde seus líderes não apenas desafiam constantemente a lógica predominante de seus setores, mas repensam a todo o momento a lógica de seu próprio sucesso (TAYLOR; LaBARRE, 2008).

Em comum, o ING Direct, a Southwest e a HBO possuem o fato de haver se desenvolvido independente do cenário econômico ser mais ou menos favorável. Além delas, várias outras empresas poderiam ser citadas, como as norteamericanas Dell - uma fabricante de computadores que vem crescendo apesar de toda a volatibilidade de o mercado -; Google - uma ferramenta de busca criada a partir de um projeto de doutorado dos então estudantes da Universidade de Stanford Larry Page e Sergey Brin, lançada em 1998, no auge da crise das empresas pontocom -; e Craigslist - um website de classificados que se tornou o favorito dos internautas.

\section{Inovações Gerando Desenvolvimento Econômico no Brasil}

A revista Fast Company publicou em sua edição de março de 2014 uma lista com as dez maiores empresas inovadoras da América do Sul. Tais empresas estão no topo em inovação, com propostas que dão suporte a diversas mudanças ao redor do globo. Dentre elas, cinco estão instaladas no Brasil (CADERNO DE ECONOMIA, 2014).

Considerada a maior inovadora da América do Sul por conseguir retirar o óleo do plástico, a Braskem, empresa do ramo de petroquímica sediada em São Paulo, foi fundada em 2002 a partir da aquisição da Central de Matérias-Primas do pólo Petroquímico do Rio Grande do Sul (Copesul), da PPH e da Poliolefinas pela Odebrecht Petroquímica. Essa integração criou a OPP Petroquímica S.A. Com a aquisição da Salgema e da CPC, surgiu a Trikem S.A. Por fim, quando a Odebrecht assumiu o controle da Central Petroquímica de Camaçari (Copene), a fusão dessa última com a OPP e Trikem deu origem à Braskem. Para justificar o título recebido, a petroquímica substituiu o petróleo pela cana de açúcar como matéria-prima, dando origem ao chamado plástico verde. 
Atualmente a empresa produz cerca de 200 mil toneladas desse produto (CADERNO DE ECONOMIA, 2014).

A BCMF Arquitetos, empresa mineira fundada em 2001, figura no ranking das maiores inovadoras do país por ter projetado o primeiro estádio abastecido com energia solar no mundo. Entre as instituições que se envolveram e ainda se envolvem com a Copa do Mundo do Brasil, de 2014, e as Olimpíadas do Rio de Janeiro, em 2016, a BCMF é a única do ramo de arquitetura. Sua principal inovação foi ter idealizado um novo telhado ao Estádio do Mineirão, em Belo Horizonte, equipando-o com um painel solar de 1,4 MW, tornando-o o primeiro estádio completamente movido a energia solar. De forma análoga, a Magazine Luiza, empresa brasileira com sede em Franca, São Paulo, fundada há mais de 50 anos, sendo a nona maior empresa varejista do país segundo ranking do Instituto Brasileiro de Executivos de Varejo e Mercado de Consumo (Ibevar) em 2012, entrou no seleto grupo das maiores inovadoras sul-americana por sua liderança no comércio eletrônico no País e pela sua penetração em mercados não muito amplos (pequenas cidades e favelas). O modelo de loja virtual foi introduzido pela rede nos anos 1990. Nesse segmento, os clientes podem experimentar os produtos em lojas físicas e, posteriormente, encomendálos pela Internet. Além desse destaque, em 2013 a primeira franquia da empresa em uma favela foi inaugurada no bairro de Heliópolis, na cidade de São Paulo (CADERNO DE ECONOMIA, 2014).

Outra empresa nacional merecedora de destaque por seu caráter inovador é a catarinense ContaAzul, desenvolvedora de sistemas de gestão online para micro e pequenas empresas. Através da elaboração e produção de um software de contabilidade online específico para o País, que emprega recursos de cloud computing (computação em nuvem), permitiu a diversas organizações enfrentar, com melhores resultados, o complexo e burocrático sistema fiscal brasileiro. Em 2013, a ContaAzul levou o prêmio da categoria Startup no evento "Empreendedores de Sucesso" promovido pela revista Pequenas Empresas \& Grandes Negócios, das organizações Globo. Inaugurada em 2011, a empresa fechou o ano de 2013 com uma carteira de 10 mil clientes. Para 2014, a companhia espera multiplicar este número por cinco. Em alinhamento a essa análise, encontra-se a Tátil Design de Ideias, consultoria carioca que se define como uma gestora de marcas 
que usa o design e o branding ${ }^{11}$ para criar conexões sustentáveis entre pessoas e marcas. Com escritórios no Rio e São Paulo, conta com equipe multidisciplinar de cerca de 80 profissionais. Seus projetos são considerados sustentáveis e acessíveis, tendo entre seus clientes nomes de peso como a Coca-Cola e a Procter \& Gamble. Os logotipos das Olimpíadas e das Paraolimpíadas do Rio de Janeiro foram desenvolvidos pela Tátil, sendo a empresa reconhecida pela utilização de materiais sustentáveis nos seus projetos. Nos últimos 20 anos, tornou-se reconhecida e admirada, sendo sua inclusão na relação da revista Fast Company, o ponto alto do citado reconhecimento (CADERNO DE ECONOMIA, 2014).

Todas estas empresas possuem um ponto de vista apurado sobre seus respectivos setores de atuação, oferecendo alternativas eficazes e bem definidas para o modelo estabelecido de negócios, alinhadas ao pensamento de Alan Kay, famoso cientista da computação, que disse há quase quatro décadas atrás, que a melhor maneira de prever o futuro é inventá-lo. Em

\footnotetext{
${ }^{11}$ Branding, que significa gestão de marcas, é a arte de administrar a imagem de uma empresa, dado referir-se ao nome, logo, slogan e identidade visual que representam a essência de uma empresa, produto ou serviço.
}

concordância a esta afirmação, Clayton Christensen, em seu livro "O Dilema da Inovação", chamou atenção das empresas para as inovações digitais que reformularam o funcionamento econômico de um segmento da produção, ou até mesmo de setores inteiros, criando vantagens competitivas em torno do ponto fraco de seus setores, dado que a única forma de sucesso de uma experiência inovadora é através de o êxito do pensamento (TAYLOR; LaBARRE, 2008).

\section{Considerações Finais}

A proposição que nos dias atuais a inovação possui a mesma importância que a industrialização teve para os países periféricos durante o século XX, onde, cada qual há seu tempo, tornaram-se sinônimos de desenvolvimento, norteiam essa pesquisa. Assim, as inovações impactam no desenvolvimento econômico brasileiro, sobretudo após a implementação do real como padrão monetário nacional, em 1994.

Todavia, é importante frisar que inovação é um processo contínuo, difícil, portanto, de ser mensurado, especialmente nas empresas que se caracterizam por atividades de inovação ricas em mudanças pequenas e incrementais, ao invés de 
projetos isolados e bem definidos em que mudanças consideráveis podem ser facilmente constatadas. Segundo o Manual de Oslo (OECD, 2005), inovações abrangem alterações significativas, podendo facilmente ser distinguidas de mudanças pequenas e rotineiras (no entanto, é importante citar que inovação também pode consistir de uma pequena série incremental). Além disso, outro fator que dificulta a mensuração da inovação é que os gastos com esta finalidade, via de regra, não constam de forma específica na contabilidade das empresas, o que dificulta seu cálculo. Ainda que este conjunto de fatores não impeça a mensuração das despesas com inovação, estas dificuldades devem ser consideradas quando do delineamento da pesquisa e de sua análise subsequente.

Ainda segundo o Manual de Oslo (OECD, 2005), há duas formas de colher dados sobre inovações: a abordagem "sujeito" e a abordagem "objeto". A primeira consiste no comportamento inovador da firma e em suas atividades, expondo os fatores que influenciam seu caráter inovador - passando pelas estratégias, incentivos e barreiras à inovação - dentro de um escopo de atividades de inovação, remetendo ao exame dos resultados obtidos, bem como aos efeitos da inovação sobre a firma. Já em relação à abordagem "objeto", a coleta de dados compreende inovações específicas - uma inovação significativa de algum tipo, ou essencial para uma empresa. Esta abordagem engloba a coleta de dados descritivos, qualitativos e quantitativos sobre a inovação, que serão mensurados - conforme já citado - através dos recursos direcionados à $\mathrm{P} \& \mathrm{D}$, às estatísticas de patentes, à geração e adoção de TICs, à biotecnologia e à gestão do conhecimento.

Tudo isso torna as empresas inovadoras líderes, ou postulantes à liderança, em seus respectivos ramos de atuação. Sua contribuição tanto para economia local como global se dá pela geração de empregos que promovem, pelos tributos que geram e pela sua contribuição na formação do Produto Interno Bruto (PIB) das nações em que estão situadas. Em um país como o Brasil, em que o crescimento e o desenvolvimento econômico dificilmente podem ser dissociados, ao se tornar inovadora, uma organização passa a contribuir de forma significativa com o desenvolvimento econômico nacional. 


\section{REFERÊNCIAS BIBLIOGRÁFICAS}

BELLUZZO, Luiz G. M. e ALMEIDA, Júlio. S. G. Depois da queda. São Paulo: Editora Civilização Brasileira, 2002.

CADERNO DE ECONOMIA. Braskem e Magazine Luzia estão entre maiores inovadores. Jun. 2014. Disponível em: $<$ http://economia.terra.com.br/braskem-emagazine-luiza-estao-entre-maioresinovadores>. Acesso em: 30 jun. 2014.

CASTRO, Antônio B.; POSSAS, Mário L.; PROENÇA, Adriano. Estratégias empresariais na indústria brasileira: discutindo mudanças. Rio de Janeiro: Editora Forense Universitária, 1996.

COASE, Ronald. (1937) The nature of the firm - In: Coase, Ronald. - The firm, the market, and the law. Chicago: University of Chicago Press, 1988.

COSTA, Achyles B. da. O desenvolvimento econômico na visão de Joseph Schumpeter. São Leopoldo-RS: Cadernos IHU ideias, ano $4, n^{\circ} 47$, Universidade do Vale do Rio dos Sinos, 2006 (Cadernos).

COUTINHO, Luciano, FERRAZ, João C., coords. Estudo da competitividade da indústria brasileira. Campinas: Editora Papirus, 1994.

FONSECA, Pedro C. D. Vargas: o capitalismo em construção 2.ed. São Paulo: Editora Brasiliense, 1999, p. 147247.

FURTADO, Celso. (1958) Formação Econômica do Brasil. São Paulo: Editora Nacional, 1987.

HSM MANAGEMENT. As idéias em primeiro lugar. p. 46-54, jan./fev. 1998. Disponível em: <http://www.joinville.udesc.br/portal/profes sores/seibel/materiais/HSM_janeiro_1998_2 .pdf>. Acesso em: 11 ago. 2009

$\begin{array}{lcr}\text { INSTITUTO } & \text { DE } & \text { PESQUISA } \\ \text { ECONÔMICA } & \text { APLICADA } & \text { (IPEA). }\end{array}$ Ipeadata, Brasília, DF. Disponível em: <http://www.ipeadata.gov.br>. Acesso em: 18 out. 2010.

KNIGHT, Peter T.; FERNANDES, Ciro C. C. O Projeto e-Brasil e o Programa e-Brasil. In: KNIGHT, Peter T.; FERNANDES, Ciro C. C.; (Org.). E-Brasil: um programa para acelerar o desenvolvimento socioeconômico aproveitando a convergência digital. São Caetano do Sul: Editora Yendis, 2006. cap. 1, p. 1-31.

LEMOS, Mauro. B.; CAMPOS, Bruno.; BIAZI, Elenici.; SANTOS, Fabiana. Capacitação tecnológica e catching up: o caso das regiões metropolitanas emergentes brasileiras. Revista de Economia Política, São Paulo, v. 26, n. 1, p. 59-70, 2006.

MENDES, Alexandre. TIC - Muita gente está comentando, mas você sabe o que é? Disponível em:<http://imasters.uol.com.br/artigo/8278/ gerencia/tic_-

_muita_gente_esta_comentando__ mas voce_sabe_o_que_e/ $>$. Acesso em: $29 \mathrm{abr}$. 2008.

ORGANISATION FOR ECONOMIC COOPERATION AND DEVELOPMENT (OECD). Proposed Guidelines for Collecting and Interpreting Technological Innovation Data - Manual de Oslo, terceira edição, UE, 2005.

PORTER, Michael. E. Vantagem 
competitiva. Campus: Editora Campus, 1989.

POSSAS, Maria S. Concorrência e competitividade - notas sobre estratégia e dinâmica eletiva na economia capitalista. São Paulo: Editora: Hucitec, 1999.

REZENDE, Cyro de B. Economia brasileira contemporânea. São Paulo: Editora Contexto, 1999, p. 75-152. (Coleção manuais).

REZENDE, Denis A.; FREY, Klaus. Administração estratégica e governança eletrônica na gestão urbana. Revista Eletrônica de Gestão de Negócios. SantosSP, v. 1, n. 1. p. 51-59, abr-jun. 2005. ISBN: 1809-0079.

SCHUMPETER, Joseph A. (1911). A Teoria do Desenvolvimento Econômico. Os Economistas. São Paulo: Editora Abril Cultural, abr. 1997.

SOUZA, Luiz G. Economia industrial. Edição digital. 2005. Disponível em: www.eumed.net/libros/2005/lgs-ei/

TAYLOR, William C.; LaBARRE, Polly. Inovadores em ação. Rio de Janeiro: Editora Sextante, 2008. ISBN: 978-85-7542423-0.

TIDD, Joe; BESSANT, John.; PAVITT, Keith. Gestão da Inovação. 3. ed. Porto Alegre: Bookman, 2008.

WILLIAMSON, Oliver. E. The Mechanisms of governance and management. London: Oxford University Press, 1985. 